\title{
Extended Science: a powerful tool in widening participation
}

\section{David J Harwood}

University of Plymouth, UK

\begin{abstract}
Year zero courses, as part of extended degree programmes, offer a robust and efficacious means of increasing participation in science and other areas of the university curriculum where graduate shortages have been identified, STEM subjects for example. This 23-year longitudinal study investigates the efficacy of this approach at one university and identifies the features which contribute to its success and may be transferable to other institutions and models. Quantitative and qualitative data are analysed and discussed. A particular feature of this approach is success in attracting, retaining and graduating mature returners as well as those with no prior familial history of participation in higher education. The critical importance of establishing a higher education learning culture also emerges.
\end{abstract}

Keywords: year zero; extended degree; mature returner; widening access.

\section{Introduction}

Since 1990, the student population in UK universities has changed considerably. More mature students than ever before have taken advantage of alternative routes into higher education, which emerged from initiatives both within the sector and in tertiary education (FE). The challenges facing students from diverse educational backgrounds in making a successful transition to university life are well documented (Martinez and Munday 1998; Fisher and Hood, 1987) as well as the economic consequences of universities and colleges failing to facilitate this transition (Yorke, 2000). Although there has been a great deal of progress in the admission of ethnic minorities, mature adults and women, particularly in science, there remains work to be done in increasing the participation of lower socio-economic groups in higher education (Tight, 2012). The development of foundation programmes within universities, or "Stage Zeros", has contributed strongly to 
this increased uptake as well as playing a pivotal role in the widening participation (WP) agenda (De Rennes, 1999). WP will be increasingly important in view of the tuition fee structure in the United Kingdom, where institutions who wish to charge the full amount will have to demonstrate not only effective action but also positive results in widening participation. There remain considerable challenges in reaching lower socio-economic groups and families without prior experience of higher education. Further, the financial outlay and increased risk for students taking this route needs to be justified, not least to prospective applicants (Chipperfield, S., 2012).

Extended Science at the University of Plymouth was piloted in 1990 and has continued successfully ever since. Expansion in recent years has been unprecedented and appears to have been unaffected by tuition fee increases, which was unexpected. It has also been demonstrated here, and at many other institutions, that the admission of students with non-standard qualifications to universities does not result in a lowering of academic standards (Keane, 2011); in fact, the opposite may be demonstrated. This purpose of this paper is to document developments in curriculum design, the provision of appropriate student support and the development of students in their university academic studies. Hence, to disseminate what is believed to be best practice.

The importance not only of curriculum design but also of a logical approach to the teaching of science, taking into account the psychology of learning is well expressed by Johnstone (2000), taking the example of chemistry. Students find the physical sciences particularly difficult because of the need to embrace new concepts and build a sound understanding of a world they cannot physically see but must imagine, by building appropriate analogous models or pictures. It is also notable that this subject area has remained for the most part the preserve of white, traditional age students, predominantly from professional and managerial backgrounds (Smith and White, 2011). Hence, support for learning plays a critical role in confidence building and learner development. Further, it is necessary to understand the aims and aspirations of mature students in particular who have little or no recent educational experience and often no familial background in higher education (Laing et al., 2005). Foster et al. (2012) identified confidence in the ability to learn and study as a key feature in student retention in a recent Higher Education Academy study.

The efficacy of our approach may be demonstrated by objectively measuring student performance and progression. With over 22 years of data to call upon, there is strong 
statistical evidence of the vitality and fitness for purpose of year zeros in effectively widening participation in university education. Changes to the university fees structure have increased the need to demonstrate value for money, as well as meeting the major challenge of maintaining graduate supply in areas of perceived shortage, such as the STEM subjects.

In parallel, over the same time period, Access to Higher Education Courses in Further Education colleges developed. These too played an important role in widening access (Harwood and Harwood, 2004) and have been particularly successful when developed in close partnership with local Higher Education institutions. The University of Plymouth Higher Education Learning Partnership CETL was a good example of this, which also benefitted from close collaboration with the Open College Network. Further, there have been continual new developments in secondary education: baccalaureates; advanced GNVQs; AVCEs and level 3 diplomas (Wellings et al., 2010). Although having more applied and vocational foci respectively than traditional ' $A$ ' levels, these qualifications are increasingly recognised, valued and accepted by university admissions tutors and can be suitable for direct entry to degree programmes.

Post-16 educational routes are likely to continue to diversify. The introduction of foundation degree programmes, a logical extension of the more vocational post-GCSE developments, is illustrative of this. Where these courses and pathways are unsuitable for direct entry to honours degree programmes in the sciences and elsewhere, the year zero, forming part of extended degree programmes at university is well placed to fill the "knowledge and skills gap".

University teachers have been singularly adept at developing stage one programmes and courses to meet the needs of an increasingly diverse student body (Ellis and Allan, 2008) but the limitations posed by a three-year degree programme and the need to maintain high academic standards have made it necessary to consider how best to adapt student support measures and procedures to adjust to these changes. In the first decade of this study, HEFCE data indicated that although participation rates in higher education had increased from approximately 15 to $30 \%$, the non-completion rate increased marginally from 14 to $18 \%$. The fact that retention rates have continued to improve across the sector, with current participation rates around $44 \%$ is testimony to the success of these developments. The emphasis on transition is justified because the vast majority of non- 
completion manifested as withdrawal during the first year of university study (Yorke, 1999). There was considerable emphasis in the early days on the updating of key graduate attributes and skills. However, this was essentially a deficiency model based approach (Wingate, 2007) and carried with it the danger of remedying only those problems which were overt and filling gaps. A more holistic approach was warranted with support for learning which builds confidence in an individual, together with encouragement for the student to take increasing responsibility for their own learning; in short, a developmental model for learning. When considering graduation from university, previous academic attainment is a useful predictor but also important are factors such as integration and selfefficacy (McKenzie and Schweitzer, 2010). Where the majority of students lack recent experience of the subject and/or educational achievement, student development in terms of confidence as well as competence is fundamental (Smith and Naylor, 2001). Classes in which students feel comfortable and are encouraged to ask questions in a supportive environment are also important. (Gasiewski et al., 2012).

Year zero programmes are now delivered by more than 55 Higher Education Institutions and allow university degrees to be accessible to a much wider range of students than was previously possible. This is not essentially a new idea and has been used by the Open University since its early days (Taylor, 1981). However, it was not until the early 1990s that large-scale experimentation was carried out at campus based universities. Many of these foundered on the flawed idea that such educational activities were best delegated to the further education sector, where level three teaching is common (facilitated by partner college networks). However, this model inadvertently encountered significant cultural transition-related learning difficulties, which meant that successful progression at university was lower than expected, especially in comparison with direct ' $A$ ' level entrants. Learning culture is not simply the curriculum, course or learning environment but rather the cultural practice of learning (James, 2001). Hence, to engender a higher education learning culture in an institution whose primary focus is not higher education is challenging. Moreover, as many institutions have discovered, students wish, wherever possible, to come to university in order to begin their HE studies and overwhelmingly choose the university campus version rather than the partner college alternative. In the period 2007-2012, for example, 25 out of 27 students living roughly equidistant from a partner college and the university campus elected to take the university based option. 
The status of being a university student appears to be a key factor here based on student surveys. Local provision is important for those for whom the step of direct entry to university is too great. This is very well addressed by the provision of Access to Higher Education courses, being part-time and often flexibly delivered. However, even with the status of university students, although not actually on campus, there are still residual issues around identity as well as transition and this appears to be why study on-campus is widely preferred by students.

Year zero provision has contributed very significantly to widening participation in a number of institutions. There has also been considerable success with year zero courses internationally (Mabila, 2006). They continue to expand and are likely to continue to be important, if not key, in many WP strategies. It is therefore of considerable value to understand as precisely as possible how successful progression has been consistently achieved in a one-year programme where practically no prior knowledge of science is required or assumed. Further, the subsequent performance of these students needs to be compared with that of their direct entry peers taking the same courses so as to ensure that progression in the two cohorts is comparable.

The model of student support is also explained and it is hoped that such dissemination will contribute to the continuing success of this mode of entry into higher education, particularly in subject areas such as STEM where there is an ongoing shortfall of graduates.

\section{Methodology}

Two sources of student data were available for interrogation: the university student records system (Unit E) and course spreadsheets for each year (stored securely). The latter contained most detail, including marks for individual pieces of coursework. Data from these spreadsheets were transferred to Microsoft Access and anonymised using student registration numbers as identifiers in order to allow tracking of progression through subsequent stages of study and graduation. Post-university progression data was also included, where known. The data was verified and "cleaned" by comparison with the University Student Record System. This was a time-consuming task, because internal changes of course necessitated individual tracking, but necessary as it allowed, for 
example, subject transfers, years out and reasons for non-progression to be discovered. Quantitative data on progression was then compiled, comparing marks gained at year zero with progression and degree classification obtained. Mature and non-mature student data was compared. Once the subject mix of stage zero had been determined, it was then possible to normalise data for direct entry students in order to make direct comparisons of performance on a subject basis. Details of this are beyond the scope of this paper but the normalised data was able to provide a valid control for this study.

The main research questions were:

- Does the extended year adequately prepare non-standard students for their subsequent undergraduate studies?

- How do extended degree students compare with their direct entry peers in terms of progression and results at graduation?

- What systems of support and teaching methodologies can be identified which facilitate student progression and could be applied to later stages (stage one for example) and more widely across the sector?

The first two questions could be adequately answered from analysis of the databases alone but the latter required additional evidence. This was gathered using semi-structured interviews with former stage zero students both after graduation and during their undergraduate studies. Anonymity was guaranteed and standard ethical procedures were followed. As a result of these interviews, some students volunteered to tell their stories to camera and appear on the national Life Pilot web site (www.Lifepilot.ac.uk - developed by Western Vocational Progression Consortium) as an inspiration to others. The interviews were transcribed and the transcriptions anonymised before textual analysis with NVivo software, which allowed words as well as phrases to be searched and quantified in context, in order to ensure that meaning was not misconstrued. In the following sections it seems logical to present results and discuss them in the narrative rather than separate the two. 


\section{The Extended Science Programme}

This programme was developed in 1990 as a means of realising the aspirations of an increasing number of non-standard ' $A$ ' level applicants for degree programmes in science, focussing on the needs of mature student entrants who have continued to apply in increasing numbers. Students may have appropriate qualifications in science but these have typically been gained sometime in the past. Most frequently, however, mature applicants have little or no formal educational qualifications, post-GCSE or ' $O$ ' level. Nevertheless, many have considerable intelligence, aptitude and the ability to succeed in higher education. Given the right grounding and the necessary confidence in their abilities they do well. A 22-year longitudinal study has shown progression rates from year zero to graduate status to be in excess of $92 \%$ among students aged 21 years or over (Table 1). Mature students rapidly became the majority of the cohort which had positive effects on work ethic and motivation for all students on the course and, given their excellent progression rates, this may be regarded as a significant contributor to its success. It is apparent the proportion of mature students has declined recently and progression rates have declined significantly (as a result of numerical expansion of the course). However, the pass rate has remained consistent, so it may be concluded that younger students are more likely to move institutions than their older counterparts for various reasons, not least familial and cultural ties.

Approximately one third of the cohort is typically between 18 and 20 years of age. These students were admitted only with post-GCSE qualifications; normally but not exclusively ' $A$ ' levels, with grades which may be high enough for university entrance but in different subjects than usual for the degree concerned. Some had appropriate subject combinations but without the grades demanded. For this younger fraction of the cohort, progression rates were comparable with those for stage one of science degrees, around $83 \%$. In recent years this has improved to $87 \%$, the mean for $2008-2011$ for this fraction of the cohort.

Taken as a whole, the 22-year mean progression rate for the Extended Science course was $86.5 \%$. This figure alone would be meaningless if subsequent undergraduate performance failed to match that of direct entry students. However, the data demonstrates that former Extended Science students not only performed as well as their direct entry peers but tended to fare better in terms of degree classifications with a statistically significant increase in upper seconds obtained in most subject areas (Table 3: overall 
38.34\% from Extended Science compared to 36.3\% from the Faculty, matched by subject, $\mathrm{p}=0.0347$ using a standard t test). Drop-out rates at stages one and two are also significantly lower. Student feedback (whole cohort, using optically read forms) and semistructured interviews (conducted with 50 randomly selected former Extended Science students from the 2005 - 2010 cohorts) strongly suggest that this may be attributed to increased time at university, becoming more immersed in the learning culture; the oneyear advantage given by the extended degree.

In order to address the needs of the various types of student on the programme, the Extended Science curriculum was developed around a knowledge base which addresses the fundamentals of biology, chemistry and physics, together with increased learning and study support compared with the norm for stage one. This increased support was focussed on the first (autumn) term with support in the spring term similar to that of stage one students. Timetabled tutorials were used in some subjects, mathematics for example. In the sciences, laboratory classes were designed to relieve time pressure (often an unhelpful feature of undergraduate laboratory classes) as well as to allow for informal tutorial and workshop activities. Experiments were closely correlated to the curriculum so that new ideas and concepts could be effectively reinforced and misconceptions addressed. Particular attention was paid to two areas defined by Meyer and Land (2006):

1. Threshold concepts; concepts which assist students in grasping and understanding difficult core concepts which constitute a significant barrier to further learning.

2. Troublesome knowledge: areas of the curriculum which students tend to find difficult. Examples from chemistry would be stereochemistry and chemical equilibria.

In this way it has proved possible to prepare students well for study at degree level without assuming any prior knowledge of science, in a single year. The success of the programme in achieving this ambitious aim has been demonstrated by the progression record of Extended Science students both within science as well as degree programmes in other faculties.

The number of progression routes has continued to increase across the University as more degree programmes show interest: further testimony to the continued success of the 
programme. It is interesting that as well as science-based degrees, a small number of students have also progressed to social science and humanities degrees.

\section{Measurement of progression}

Progression may be measured in several ways as illustrated below. An adequate control is required and for this purpose a peer-group comparison was made with standard ' $A$ ' level, GNVQ or Access to Higher Education entrants:

1. Progression from the extended year to stage one.

2. Progression from stage one to stage two.

3. Degree classification on graduation.

4. Progression to post graduate study.

At the outset, (1) was of the greatest concern and regarded as the crucial test of the programme's "fitness for purpose". However, (2) is also critical as it is the one of the best ways to validate (1). The situation is complicated by increasing numbers of non-standard entrants to university courses year on year and in that sense the "control" must be regarded as fluid. Nevertheless, the comparison is valid because these entry routes are deemed by admissions tutors to be appropriate and their efficacy has been closely monitored over a considerable period of time.

Many teaching staff in higher education are convinced that ' $A$ ' level is not the best preparation for a degree programme. However, the vast majority of admissions tutors in the H.E. sector use 'A' level point scores as their main admissions criterion and are reluctant to 'experiment' with non-standard entrants because of the absence of significant alternatives. However, the experience of those courses with year zero students progressing into stage one is overwhelmingly positive and the establishment of a Foundation Year Network (www.foundationyear.ac.uk) with an annual conference is increasing the profile of similar courses.

It was felt important to include post graduate study (4) not least because extended degree students may suffer a financial disadvantage; the extra year's student loan debt being a significant discouragement for some graduates. Furthermore, if a student goes on to complete a programme such as MChem or MGeol, this would take a total of five years and 
may be a powerful financial disincentive. There may also be an increased tendency to spend too much time in part-time working, to the detriment of academic achievement (Robotham, 2012).

The cohorts were surveyed from September 1990 entry, the pilot year, to September 2010 and successful progression from stage zero to stage one calculated as a percentage of the whole group of engaged students (corrected for withdrawn students).

Table 1. Progression in BSc Extended Science from stage zero to stage one.

\begin{tabular}{|l|l|l|l|l|l|}
\hline $\begin{array}{l}\text { Year of } \\
\text { Entry }\end{array}$ & $\begin{array}{l}\text { Total } \\
\text { Recruited }\end{array}$ & $\begin{array}{l}\text { Pass to } \\
\text { Degree }\end{array}$ & $\begin{array}{l}\text { Credits } \\
\text { awarded }\end{array}$ & Failed & Withdrew \\
\hline 1990 & 34 & 32 & 2 & 0 & 0 \\
\hline 1991 & 73 & 60 & 10 & 0 & 3 \\
\hline 1992 & 92 & 73 & 4 & 3 & 12 \\
\hline 1993 & 118 & 95 & 4 & 2 & 17 \\
\hline 1994 & 139 & 112 & 15 & 2 & 10 \\
\hline 1995 & 160 & 117 & 16 & 14 & 23 \\
\hline 1996 & 163 & 118 & 4 & 18 & 23 \\
\hline 1997 & 168 & 132 & 13 & 12 & 11 \\
\hline 1998 & 161 & 114 & 20 & 13 & 15 \\
\hline 1999 & 158 & 127 & 10 & 7 & 14 \\
\hline 2000 & 118 & 97 & 4 & 14 & 5 \\
\hline 2001 & 117 & 77 & 15 & 10 & 15 \\
\hline 2002 & 148 & 108 & 5 & 12 & 23 \\
\hline 2003 & 138 & 104 & 10 & 18 & 6 \\
\hline 2004 & 123 & 83 & 14 & 14 & 12 \\
\hline 2005 & 146 & 96 & 10 & 16 & 22 \\
\hline 2006 & 118 & 86 & 11 & 12 & 9 \\
\hline 2007 & 102 & 80 & 6 & 5 & 11 \\
\hline 2008 & 147 & 108 & 17 & 11 & 11 \\
\hline 2009 & 153 & 118 & 12 & 17 & 6 \\
\hline 2010 & 152 & 122 & 17 & 11 & 2 \\
\hline & & & & & \\
\hline
\end{tabular}


One of the most notable features is that withdrawal and failure rates are very low compared with Access to HE courses and have been significantly lower than stage one drop-out across science degrees nationally. The mean withdrawal rate was $8 \%$ and the mean failure rate only $5 \%$, roughly half of the stage one drop-out rate nationally for the period (HEFCE). The main reason for this is the considerable effort expended in recruiting mature students to the programme. More detailed analysis revealed that withdrawals and failures came predominantly from 18-20 age-group. These students mostly entered with ' $A$ ' level grades insufficient to allow direct entry to stage one. It must be concluded therefore that students with more recent post-GCSE formal educational experience, find the cultural transition to university study more difficult than their more mature colleagues. Whether this is because of changes to the ' $A$ ' level curriculum is worthy of consideration in the light of studies by the Royal Society of Chemistry, who found, among other things, that breadth of knowledge had increased, very much at the expense of depth. Perhaps due to developments in first-year university curricula and student support, drop-out rates for science degrees have not increased but rather improved in recent years, which would appear to counter that assertion. University science curricula could be said to have developed successfully to deal with changes in the academic backgrounds of entrants.

\section{Student tracking}

Student tracking; the identification of students at risk of failure as early as possible in the year, certainly within the first term, is a vital component of support. Laboratory and lecture attendance registers were constantly monitored. Laboratory attendance records are precise whereas lecture registers may not be robust for a particular session but nevertheless provide a reliable pattern. Students identified from these sources were contacted by email and followed up by letter to see if help was required. In $70 \%$ of cases, a positive response was either elicited or the student's attendance spontaneously returned to acceptable levels. In the other $30 \%$ of cases, a follow-up letter was sent to the term-time and home addresses of the student, formally requiring an appointment with their personal tutor to be made within seven days. This resulted in positive replies from the majority together with a positive change in behaviour with or without tutor intervention. A small minority of students formally notified suspension of study, or complete withdrawal, following appropriate discussions. Since the programme manager acts as personal tutor for the cohort (because of the wide diversity of degree pathways followed subsequently by students) managing this process with administrative support was relatively straightforward. 


\section{Partner colleges and learning culture}

Internal consistency is an important measure of whether partner colleges have been successful in engendering a higher education learning culture. This alone is not enough and progression rates for the latter stages were therefore also monitored. Table 2 gives the year zero pass rates for university and partner-college cohorts.

Table 2. Percentage pass rates to degree programmes of Extended Science students from the university partner college cohorts.

\begin{tabular}{|l|l|l|}
\hline Year of Entry & University & Partner College \\
\hline 1990 & 94 & No cohort \\
\hline 1991 & 86 & 77 \\
\hline 1992 & 91 & 85 \\
\hline 1993 & 94 & 77 \\
\hline 1994 & 87 & 85 \\
\hline 1995 & 80 & 88 \\
\hline 1996 & 84 & 57 \\
\hline 1997 & 84 & 85 \\
\hline 1998 & 78 & 82 \\
\hline 1999 & 88 & 89 \\
\hline 2000 & 86 & 87 \\
\hline 2001 & 76 & 88 \\
\hline 2002 & 86 & 92 \\
\hline 2003 & 79 & 69 \\
\hline 2004 & 75 & 78 \\
\hline 2005 & 77 & 92 \\
\hline 2006 & 79 & No Cohort \\
\hline 2007 & 79 & No cohort \\
\hline 2008 & 81 & No cohort \\
\hline 2009 & 80 & 72 \\
\hline 2010 & 81 & 65 \\
\hline
\end{tabular}

Note: withdrawn students were not deemed to have fully engaged and are excluded. 
There were no statistically significant differences between the two, either at stage zero or during later stages, although mean pass rates at the colleges tended to be slightly higher. Semi-structured interviews with student cohorts and six college staff indicated that they felt smaller group size, i.e. low student-staff ratio, was an advantage. However, partner college students did report lower confidence in their ability to study at university compared with those who had studied on campus (68\% confident or very confident as opposed to $85 \%$ of the university cohort). These data were collected by on-line questionnaire early in stage one at university, for the 2005 - 2010 cohorts (340 responses). Progression records indicate that partner college students did in fact do as well as their university counterparts.

\section{Subsequent progression}

As well as measuring progression from stage zero to stage one, it was also necessary to evaluate student progress in later stages of study, since a high pass rate at stage zero would be meaningless if drop-out rates at later stages were higher than normal. Students who were admitted prior to 2010 have now graduated, unless they have taken time out or have taken a route via a sub-degree programme only allowing entry to later stages of a university degree. The September 1990 to 2010 entrants were also tracked in terms of the degree classification obtained at graduation (Table 3). These students would normally have been expected to graduate between July 1994 and July 2014 . A number took an extra year or more for various reasons: the need to have a year out, earning, in order to complete their studies, personal circumstances dictating a necessary break in study and, in a minority of cases, electing to repeat referred modules on a part-time basis. In all, over half of the students (51\%) gained at least an upper second class degree. Given the entry qualifications and educational background of these students this represents a considerable achievement.

96\% of former Extended Science students gained a higher education qualification, 93.4\% of the total gained a degree and $88.4 \%$ graduated with honours.

\section{Table 3. Qualifications obtained at graduation.}




\begin{tabular}{|c|c|c|c|c|c|c|c|}
\hline $\begin{array}{l}\text { Year } \\
\text { Graduated }\end{array}$ & $\begin{array}{l}\mathbf{1}^{\text {st }} \\
\text { First- } \\
\text { class } \\
\text { honours }\end{array}$ & $\begin{array}{l}\text { 2:1 } \\
\text { Second- } \\
\text { class } \\
\text { honours, } \\
\text { upper } \\
\text { division }\end{array}$ & $\begin{array}{l}2: 2 \\
\text { Second- } \\
\text { class } \\
\text { honours, } \\
\text { lower } \\
\text { division }\end{array}$ & $\begin{array}{l}3^{\text {rd }} \\
\text { Third- } \\
\text { class } \\
\text { honours }\end{array}$ & $\begin{array}{l}\text { Degree } \\
\text { Ordinary } \\
\text { degree } \\
\text { (pass) }\end{array}$ & Dip HE & Withdrew \\
\hline 1994 & $7.5(2)$ & $41(11)$ & $29.6(8)$ & $11.1(3)$ & $3.3(1)$ & $3.3(1)$ & $3.3(1)$ \\
\hline 1995 & $13(8)$ & $37(22)$ & $33.3(20)$ & $10(6)$ & $3.3(2)$ & $3.3(2)$ & 0 \\
\hline 1996 & $15.3(9)$ & $37.3(22)$ & $40.7(24)$ & 0 & 0 & $1.6(1)$ & $5(3)$ \\
\hline 1997 & $13(12)$ & $33.7(31)$ & 32 (29) & $1(1)$ & $3.2(3)$ & $4.3(4)$ & $13(12)$ \\
\hline 1998 & $\begin{array}{l}15.2 \\
(17)\end{array}$ & $34(38)$ & 33 (37) & $3.6(4)$ & $3.6(4)$ & $2.7(3)$ & $8(9)$ \\
\hline 1999 & $\begin{array}{l}15.4 \\
(18)\end{array}$ & $34.2(40)$ & 33 (39) & $2.6(3)$ & $3.4(4)$ & $3.4(4)$ & $7.6(9)$ \\
\hline 2000 & $14.3(9)$ & $31.7(20)$ & $39.7(25)$ & $3.1(2)$ & $6.3(4)$ & $4.8(3)$ & 0 \\
\hline 2001 & $4.8(3)$ & $49.2(31)$ & $30.2(19)$ & $1.6(1)$ & $7.9(5)$ & $3.2(2)$ & $1.6(1)$ \\
\hline 2002 & $10.7(6)$ & $51.8(29)$ & $30.4(17)$ & $3.6(2)$ & $3.6(2)$ & 0 & 0 \\
\hline 2003 & $11(14)$ & $32.3(42)$ & $32.3(41)$ & $5.5(7)$ & $7.1(9)$ & $3.9(9)$ & $3.9(5)$ \\
\hline 2004 & $\begin{array}{l}10.5 \\
(12)\end{array}$ & $38.6(44)$ & $35.1(40)$ & $5.3(6)$ & $3.5(4)$ & $1.8(2)$ & $5.3(6)$ \\
\hline 2005 & $\begin{array}{l}16.1 \\
(14)\end{array}$ & $41.4(36)$ & $25.3(22)$ & $4.6(4)$ & $2.3(2)$ & $3.4(3)$ & $6.8(6)$ \\
\hline 2006 & $\begin{array}{l}21.4 \\
(18)\end{array}$ & $31(26)$ & $28.6(24)$ & $6(5)$ & $8.3(7)$ & $4.7(4)$ & 0 \\
\hline 2007 & $\begin{array}{l}18.6 \\
(11)\end{array}$ & $33.9(20)$ & $23.7(14)$ & $1.7(1)$ & $18.6(11)$ & $1.7(1)$ & $1.7(1)$ \\
\hline 2008 & $15(9)$ & $48.3(29)$ & $28.8(17)$ & $3.4(2)$ & $1.7(1)$ & $1.7(1)$ & 0 \\
\hline 2009 & $\begin{array}{l}14.3 \\
(12)\end{array}$ & $31(26)$ & $36.9(31)$ & $9.5(8)$ & $3.6(3)$ & 0 & $4.8(4)$ \\
\hline 2010 & $\begin{array}{l}13.5 \\
(10)\end{array}$ & $32.4(24)$ & $39.2(29)$ & $2.7(2)$ & $5.4(4)$ & 0 & $6.7(5)$ \\
\hline Mean \% & 13.51 & 37.58 & 32.46 & 4.43 & 5.01 & 2.58 & 3.98 \\
\hline $\begin{array}{l}\text { Standard } \\
\text { deviation }\end{array}$ & 3.9 & 6.65 & 4.79 & 3.19 & 4.13 & 1.58 & 3.71 \\
\hline
\end{tabular}

(Percentages with numbers in brackets) 


\section{Stage one withdrawal rates}

As mentioned previously, the progression of students from stage one to stage two was regarded as a critical test of the stage zero in terms of preparation for degree level study. The withdrawals (right hand column above) were found to be generally less than ten percent of the number passing to degree and most frequently under $5 \%$ of the cohort. This is most satisfactory in that it is well below the withdrawal rate from stage one of any of the degree programmes open to extended students and tends to support the students' perception of the advantages of the extra year.

As expected, the majority of withdrawals took place at the end of stage one. Of the 34 students withdrawing from the first six cohorts, 31 of these withdrew at the end of stage one. This figure includes those who took a year out to earn money and intended to return. It has not proved possible to track enough of these students to date so that the figures are presented simply as withdrawals, although a significant number have returned and completed their studies so that the true withdrawal rate is lower than the $3.98 \%$ indicated.

\section{Postgraduate study}

As would be expected from the first class and upper second honours graduates (more than half of the students), a good number have gone on to post graduate study. To date 62 students are known to have successfully completed PhD, Masters, or Postgraduate diploma (including PGCE) qualifications. Since these qualifications take between one and three years to complete and the degree classification required for entry to the various postgraduate programmes is variable, it is not possible to calculate exactly the size of the pool from which these students are drawn. Many students take postgraduate degrees at different institutions and only of a fraction of these are known so that the true figure is certain to be higher. This does however demonstrate that these students are not academically disadvantaged compared with students from other backgrounds and that the extra year is advantageous. These higher degrees have been taken at a wide variety of institutions, including Russell Group universities. Whilst this does not necessarily indicate an equality of access, it does appear that the extended degree route is no barrier to academic success.

\section{Comparison with 'A' level entrants}

It is useful to compare the performance of Extended Science students with those from typical 'A' level backgrounds on various degree programmes. Since the number of degree 
programmes admitting these students is so large, there are few programmes where a statistically valid analysis of data is possible. This situation will improve as more students graduate.

It is, however, possible to analyse degree classifications obtained across the Faculty of Science and compare this with the performance of BSc Extended Science students. These figures are presented in Table 4 for the first six cohorts.

Table 4. Degree classifications obtained in Science (expressed as percentages of the total cohort).

\begin{tabular}{|l|l|l|l|l|l|}
\hline $\begin{array}{l}\text { Year } \\
\text { Graduated }\end{array}$ & $\begin{array}{l}\mathbf{1}^{\text {st }} \\
\text { First-class } \\
\text { honours }\end{array}$ & $\begin{array}{l}\mathbf{2 : 1} \\
\text { Second- } \\
\text { class } \\
\text { honours, } \\
\text { upper } \\
\text { division }\end{array}$ & $\begin{array}{l}\mathbf{2 : 2} \\
\text { Second- } \\
\text { class } \\
\text { honours, } \\
\text { lower } \\
\text { division }\end{array}$ & $\begin{array}{l}\mathbf{3}^{\text {rd }} \\
\text { Third-class } \\
\text { honours }\end{array}$ & $\begin{array}{l}\text { Degree } \\
\text { Ordinary } \\
\text { degree } \\
\text { (pass) }\end{array}$ \\
\hline 1994 & $7(5)$ & $41(41)$ & $30(44)$ & $11(4)$ & $7(6)$ \\
\hline 1995 & $13(9)$ & $37(35)$ & $33(50)$ & $10(2)$ & $7(5)$ \\
\hline 1996 & $15(7)$ & $37(34)$ & $41(40)$ & $0(3)$ & $2(9)$ \\
\hline 1997 & $13(3)$ & $34(40)$ & $32(50)$ & $1(2)$ & $8(6)$ \\
\hline 1998 & $15(8)$ & $34(35)$ & $33(41)$ & $4(5)$ & $6(8)$ \\
\hline 1999 & $15(9)$ & $34(32)$ & $33(40)$ & $3(5)$ & $7(8)$ \\
\hline Mean & $13(6.83)$ & $\begin{array}{l}36.17 \\
(36.17)\end{array}$ & $\begin{array}{l}33.67 \\
(44.17)\end{array}$ & $4.83(3.5)$ & $6.17(7)$ \\
\hline $\begin{array}{l}\text { Standard } \\
\text { deviation }\end{array}$ & $3.1(2.4)$ & $2.79(3.54)$ & $3.78(4.75)$ & $4.62(1.38)$ & $2.14(1.55)$ \\
\hline
\end{tabular}

Notes: Percentage pass for the whole of the Faculty of Science in Brackets

The percentages of Extended Science students obtaining a certain degree classification are remarkably consistent year on year, comparing very favourably with those for the faculty of science as a whole. A significantly higher percentage of firsts were gained by former Extended Science students (mean 13\%) than direct ' $A$ ' level entrants (mean 6.83\%) $(p=0.00323)$ and slightly more upper seconds. Fewer lower second class degrees were obtained by these students ( $33.67 \%$ as opposed to $44.14 \%, p=0.0163$ ) with thirds and pass degree figures being not significantly different. 
During the last decade $(2000-2010)$, the number of firsts gained by faculty of science graduates increased to the extent that the two cohorts were not statistically distinguishable in terms of firsts gained; the Extended Science firsts have remained broadly constant. In terms of upper seconds though, Extended Science students performed statistically significantly better during this period $(p=0.0107)$. The mean classifications obtained by these cohorts are given in Table 5 below.

Table 5. A comparison of degree classifications obtained from 2000-2010 (normalised for subjects studied).

\begin{tabular}{|l|l|l|}
\hline $\begin{array}{l}\text { Degree } \\
\text { Classification }\end{array}$ & $\begin{array}{l}\text { Graduates } \\
\text { from Extended } \\
\text { Science }\end{array}$ & Faculty of Science \\
\hline First & $11.2 \%$ & $12.1 \%$ \\
\hline Upper Second & $41.5 \%$ & $36.3 \%$ \\
\hline Lower Second & $37.1 \%$ & $27.5 \%$ \\
\hline Third & $2.9 \%$ & $3.5 \%$ \\
\hline Cert HE & $0.5 \%$ & $2.2 \%$ \\
\hline Deg & $4.8 \%$ & $2.2 \%$ \\
\hline Dip & $0.9 \%$ & $2.0 \%$ \\
\hline Fail & $0.5 \%$ & $1.0 \%$ \\
\hline Other & $0.5 \%$ & $12.9 \%$ \\
\hline
\end{tabular}

One reason for the improvement in the faculty figures for firsts is believed to be improvements in support for stage one students, a number of which were introduced as a result of lessons learned from stage zero. Students have reported in annual feedback questionnaires, feeling more confident in their studies in subsequent stages since student support has improved (specifically increased tutorial time and improved access to personal and academic tutors were mentioned).

Over the 20 years of graduation covered by this study, BSc Extended Science students have been more likely than their peers with 'A' levels to obtain at least an upper second class honours degree. At the lower end, third and pass/ordinary degree, there were no statistically significant differences between Extended Science students and the predominantly 'A' level cohort. 
Table 5 gives a summary of the progression and degree classifications obtained by former Extended Science students from the Faculty of Science. As a comparison, the results for the Faculty as a whole are also given. The data is broken down into the categories published and used by the University in the relevant Unit E reports, which form the basis for annual programme monitoring.

There are currently around $\mathbf{4 7 0}$ former Extended Science students on stages one to three of undergraduate programmes.

$52.7 \%$ of former Extended Science students graduated with a first or upper second class honours degree between 1993 and 2010, compared with 48.4\% from the Faculty as a whole. This is statistically significant $(p=0.0167)$.

The Faculty figure for "other" represents those students who do not fit into the categories above and includes repeat and completing students. This figure is likely therefore to increase the lower second and below percentages for the Faculty when comparing strictly like with like to a greater extent than the higher classifications.

Of the 2248 students taking Extended Science, 1997 progressed to programmes run by the Faculty of Science (89\%).

\section{Factors influencing progression}

A series of semi-structured interviews were conducted with 56 past students, both graduates and those in stages one to three. These students came from eight different cohorts between the years 1994 to 2009. They suggested that the following factors contributed strongly to the success of the Extended Science programme:

- The extra year at university.

- Development of teaching and learning skills from stage zero.

- Motivation to succeed having given up a career.

- Strong desire to succeed having embarked on a four-year programme.

- Motivation to grasp the chance to get a degree (linked by the majority to improved employment prospects).

- Confidence in their ability to study at this level engendered by Extended Science. 
- Practice in university examinations.

The Extended Science programme at this university compares favourably with other similar programmes at 55 different institutions but detailed progression data for these programmes was unavailable. None of the four programmes for which we have seen overall figures currently matches the first/upper second class degree attainment. The reason for this is unknown and the sample is too small for meaningful analysis but it could be speculated that since most have come into being only during the past decade, their stage of development is not sufficiently advanced to enable a fair comparison. The longer-lived programmes have progression to degree rates averaging $77 \%$ of the cohort (Extended Science 78 - 85\%) but the first/upper second profile is below $50 \%$. Generally, programmes which are taught on University Campuses by departmental academic staff have been the most successful. Programmes franchised to partner colleges at university tend to be either less successful or short lived and certainly less popular in terms of UCAS applications. The reasons identified for this lack of success are strongly related to learning culture. It is extremely difficult to generate a University learning culture in a non-university setting. One partner college in Cornwall has been partially successful in establishing a separate Higher Education unit and a second in Devon has recently instigated a similar model. However, where honours and foundation degree students work together in the same learning facilities alongside further education students, it is difficult to compare the two groups since they are not truly separate. Cross fertilisation may have benefits but for whom and why, are avenues for further research.

\section{Conclusion}

The BSc Extended Science Programme has been shown to be an excellent preparation for higher education. The above analysis demonstrates conclusively that a lack of formal or recent educational qualifications is by no means a barrier to graduate status. Roughly $63 \%$ of the extended degree students in this 22-year study were mature, that is of 21 years of age or over (ranging from $62-75 \%$ of the cohort) and the vast majority of these lacked traditional qualifications such as 'A' level. Most had no post-GCSE level science. Nevertheless, their results and progression were comparable with, or in some cases better than their direct entry counterparts. 
It has also been demonstrated that ' $A$ ' level entrants with unusual subject combinations or unsatisfactory grades can benefit from a stage zero at university. Hence good students who made unconventional ' $A$ ' level choices, or just missed the required grades in more standard subjects, are able to gain good science degrees with an extra year's preparation.

Despite their shortcomings in terms of formal qualifications, Extended Science students were more likely to gain a first or upper second class honours degree than direct stage one entrants with the traditional ' $A$ ' level subjects and grades. Even in subject areas such as chemistry which are widely regarded as the more difficult, this holds true. Strong student motivation, a particular attribute of mature students and prolonged exposure to the university learning culture are significant factors in the success of year zeros. A high level of student support, particularly during the critical first term at university is also demonstrably important. No particular student support measures appeared to be significantly better than others for stage zero students but increased frequency of laboratories, formal assessments, good quality feedback, tutorial opportunities and revision workshops compared with later stages of study, together with a strong and more overt personal tutor system were all factors cited by students as important in their learning development.

\section{References}

Chipperfield, S. (2012) 'Self-preservation and the individualisation of risk in universitybased foundation course students', Journal of Further and Higher Education, 37(5), pp. 623-642. http://dx.doi.org/10.1080/0309877X.2011.645472

De Rennes, J. (1999) 'Maintaining spaces for adult learners in science', Standing Conference on University Teaching and Research in the Education of Adults (SCUTREA): 29th Annual Conference. University of Warwick, Warwick 5-7 July [Online]. Available at: http://www.leeds.ac.uk/educol/documents/000000987.doc (Accessed: 17 September 2016).

Ellis, R. and Allan, R. (2008) 'Learning styles and learning strategies: assessing their impact on science foundation students', Widening Participation and Lifelong Learning, 10(2), pp. 41-50. Available at: 
http://www.ingentaconnect.com/content/openu/jwpll/2008/00000010/00000002/art0 $\underline{0005}$

Fisher, S. and Hood, B. (1987) 'The stress of the transition to university: a longitudinal study of psychological disturbance, absent-mindedness and vulnerability to homesickness', British Journal of Psychology, 78(4), pp. 425-441. http://dx.doi.org/10.1111/j.2044-8295.1987.tb02260.x

Foster, E., Lawther, S., Keenan, C., Bates, N., Colley, B. and Lefever, R. (2012), Higher education: engagement and retention (the HERE project) - final report. Higher Education Academy, January. Available at: http://www.heacademy.ac.uk/resources/detail/what-works-studentretention/HERE Project What Works Final Report (Accessed: 17 September 2016).

Foundation Year Network (2014) Available at: www.foundationyear.ac.uk (Accessed: 17 September 2016).

Gasiewski, J., Eagan, K., Garcia, G., Hurtado, S. and Chang, M. (2012) 'From gatekeeping to engagement: a multicontextual, mixed method study of student academic engagement in introductory STEM courses', Research in Higher Education, 53(2), pp. 229-261. http://dx.doi.org/10.1007/s11162-011-9247-y

Harwood, David and Harwood June. (2004) Higher education in further education: delivering higher education in a further education context-a study of five South West colleges. Journal of Further and Higher Education Vol. 28, Iss. 2,

James, D. and Bloomer, M. (2001) 'Cultures of learning and the learning of cultures', Cultures of Learning Conference. University of Bristol, Bristol 22 April [Online]. Available at:

http://education.exeter.ac.uk/tlc/docs/publications/BR DJA PUB 04.01.doc (Accessed 17 September 2016).

Johnstone, A. (2000) 'Teaching of chemistry - logical or psychological?', Chemistry Education, 1(1), pp. 9-15. http://dx.doi.org/10.1039/A9RP90001B 
Keane, E. (2011) 'Dependence-deconstruction: widening participation and traditional-entry students transitioning from school to higher education in Ireland', Teaching in Higher Education, 16(6), pp. 707-718.

http://dx.doi.org/10.1080/13562517.2011.570437

Laing, C., Robinson, A. and Johnston, V. (2005) 'Managing the transition into higher education: an on-line spiral induction programme', Active Learning in Higher Education, 6(3), pp. 243-255. http://dx.doi.org/10.1177/1469787405059575

Martinez, P. and Munday, F. (1998) 9000 voices: student persistence and drop-out in further education. London: Further Education Development Agency. (ERIC Number: ED427169). Available at: http://files.eric.ed.gov/fulltext/ED427169.pdf

Mabila, T., Malatje, S., Addo-Bediako, A., Kazeni, M. and Mathabatha, S. (2006) 'The role of foundation programmes in science education: The UNIFY programme at the University of Limpopo, South Africa', International Journal of Educational Development, 26(3), pp. 295-304. http://dx.doi.org/10.1016/j.ijedudev.2005.08.004

McKenzie, K. and Schweitzer, R. (2010) 'Who succeeds at university? Factors predicting academic performance in first year Australian university students', Higher Education Research and Development, 20(1), pp. 21-33. http://dx.doi.org/10.1080/07924360120043621

Robotham, D. (2012) 'Student part-time employment: characteristics and consequences', Education + Training, 54(1), pp. 65-75. http://dx.doi.org/10.1108/00400911211198904

Sewart, David (1981). Distance Teaching: A Contradiction in Terms? Teaching at a Distance, n19 p8-18 Available at: http://eric.ed.gov/?id=EJ248813

Smith, J. and Naylor R. (2001) 'Dropping out of university: a statistical analysis of the probability of withdrawal for UK university students', Journal of the Royal Statistical Society (Statistics in Society, Series A), 164(2), pp. 389-405.

http://dx.doi.org/10.1111/1467-985X.00209 
Smith, E. and White, P. (2011) 'Who is studying science? The impact of widening participation policies on the social composition of UK undergraduate science programmes', Journal of Educational Policy, 26(5), pp. 677-699.

http://dx.doi.org/10.1080/02680939.2010.540676

Tight, M. (2012) 'Widening participation: a post-war scorecard, British Journal of Educational Studies, 60(3), pp. 211-226. http://dx.doi.org/10.1080/00071005.2012.697541

Thompson, K. C. (2010), The OU Fd in Analytical Science, Chemistry and Industry, July 2010, p33

Wellings, D., Spours, K. and Ireson, J. (2010) 'Advanced GNVQs, AVCEs and level 3 diplomas in England: a motivational analysis', Research in Post-Compulsory Education, 15(4), pp. 387-403. http://dx.doi.org/10.1080/13596748.2010.526800

Western Vocational Progression Consortium (WVPC) (2013) Life Pilot. Available at: www.life-pilot.co.uk (Accessed: 17 September 2016).

Wingate, U. (2007) 'A framework for transition: supporting 'learning to learn' in higher education', Higher Education Quarterly, 61(3), pp. 391-405. http://dx.doi.org/10.1111/j.1468-2273.2007.00361.x

Yorke, M. (1999) 'Student withdrawal during the first year of higher education in England', Journal of Institutional Research in Australasia, 8(1), pp. 1-15. Available at: http://www.aair.org.au/articles/volume-8-no-1/8-1-student-withdrawal-during-thefirst-year-of-higher-education-in-england (Accessed: 17 September 2016).

Yorke, M. (2000) 'Smoothing the transition into higher education: what can be learned from student non-completion', Australasian Association for Institutional Research, 9(1), pp. 1-10. Available at: http://www.aair.org.au/articles/volume-9-no-1/9-1-smoothingthe-transition-into-higher-education-what-can-be-learned-from-student-noncompletion (Accessed: 17 September 2016). 


\section{Author details}

David Harwood is Associate Professor and Director of the Institute for Science Education at the University of Plymouth. His particular passion is teaching chemistry and he has developed expertise in communicating the subject to non-chemistry specialists. David cowrote the Stage Zero Extended Science course in 1990 and has managed the programme as well as acting as its Admissions Tutor for most of the last 25 years. He also has research interests in the Indoor Environment, liquid crystals and Fourier Transform InfraRed Spectroscopy, a technique which he helped pioneer in the 1980s. David teaches on the Chemistry and Environmental Science degree programmes and, contributes to the PGCE chemistry programme. "I still get a kick out of chemistry and real enthusiasm for being in the lab, something I hope communicates to my students. Research is fun and a wonderful thing to be able to do but it is teaching that really gets me out of bed in the mornings; to be able to do research into teaching more effectively, and put that into practice in the lab and lecture theatre, is an immense privilege". 